\title{
Negeri Berlinang Mitos (sebuah Ulasan Novel "Negeri Lima Menara" Karya Ahmad Fuadi)
}

\author{
Zulkifli Makmur \\ Sekolah Tinggi Darud Dakwah wal Irsyad Kota Makassar \\ Zulkifli.makmur@mail.ugm.ac.id
}

\begin{abstract}
Abstrak
Artikel ini merupakan sebuah pembacaan novel Negeri Lima Menara (2009) karya Ahmad Fuadi melalui pendekatan Dekonstruksi Derrida. Dari pembacaan ini, dapat mengemuka bahwa gagasan fiksi autobiografi cenderung mengarah pada konsekuensi imajinasi yang moralis. Hal ini disebabkan pengarang berusaha menghindari sisi gelap dari dirinya dengan mengangkat kegigihan hidup menggapai cita-cita. Padahal telah diketahui bahwa sebuah perjalanan mimpi saja tidak cukup dengan perjalanan moral yang lurus. Upaya menutupi itu dilakukan karena pengarang menjaga namanya di balik narasi fiksinya sendiri. Namun sejauh dia menutupi perjalanan gelapnya, selalu ada jejak untuk menguak sisi gelapnya.
\end{abstract}

\section{Pendahuluan}

"The question what was Aristotle has a simple answer.... He's born, he thought, and he died And all the rest is purely anecdote" (Derrida)

Kesuksesan tetralogi Laskar Pelangi karya Andrea Hirata merupakan gerbang lahirnya novel-novel bergenre autobiografi di awal 2000-an. Meski beberapa kritikus sastra di Indonesia enggan memberikan respon positif terhadap maraknya novel-novel bergenus kisah-diri itu, pembaca pop telah menetapkan kenikmatannnya dengan memilih fiksi autobiografi sebagai bagian koleksi rak-rak mereka (Makmur, Z; 2020). Ini merupakan sebuah fenomena dunia fiksi Indonesia yang sulit terbendung karena karya-karya autobiografi pop kini menjamur dan beberapa di antaranya best-seller dan terpampang rapi di rak depan di toko-toko buku. Dengan maraknya buku-buku autobiografi tersebut tokoh-tokoh, yang awalnya, tidak memiliki interest di dunia sastra sekali pun turut menciptakan tokoh-tokoh protagonis yang merepresentasikan dirinya di dalam teks-teks fiksi buatannya (Makmur, Z., \& Sainuddin, I. H., S; 2020).

Apakah fenomena tersebut akan berdampak positif atau sebaliknya di dalam perkembangan kesusasteraan di Indonesia? Pengulas tidak memiliki kapasitas apapun untuk memberikan justifikasi. Ulasan ini, oleh karena itu, menggunakan kerangka teoritis dekonstruksi ala Jacques Derrida dalam mengungkapkan secara umum pengaruh kuat teks-teks autobiografi 
mengkonstruksi dan memenjara imajinasi pembaca, agar pengulas mampu memetakan pengaruhpengaruh yang ditimbulkan dari maraknya novel-novel selfie ini (Makmur, Z; 2020).

Salah satu ciri utama novel autobiografi dan biografi adalah mengungkapkan masa lalu kehidupan sederhana dan perjuangan yang dilalui seseorang yang dalam kacamata arus utama dipandang berhasil meraih cita-cita mereka seperti bersekolah ke luar negeri, menjadi pejabat pejabat di negeri ini, atau pengusaha besar (Makmur, Z; 2020). Ini dapat dilihat dalam novelnovel autobiografi seperti tetralogi Laskar Pelangi, Trilogi Negeri 5 Menara, Chairul Tanjung Si Anak Singkong biografi Mimpi Satu Juta Dollar, dan trilogi Sepatu Dahlan.Ini dapat dilihat bahwa novel-novel yang telah disebutkan di atas, pada dasarnya, kecenderungan style yang digunakannya bertujuan memotivasi pembacanya. Mereka mengutamakan kutipan atau ungkapan sebagai titik awal yang memberikan pengaruh kuat bagi protaginis menjalani hidup yang penuh rintangan, salah satu di antaranya Manjaddah Wa Jadah (HERIANTO, H., Jusmiana, A., Jusmawati, J., \& Makmur, Z; 2020). Novel-novel ini dapat diasumsikan subur di satu dekade ini dikarenakan maraknya ceramah-ceramah motivasi yang sering muncul di layar kaca.

Novel Negeri 5 Menara merupakan sekuel dari Trilogi novel Negeri 5 Menara karya Ahmad Fuadi. Novel ini menceritakan sosok Alif Fikri yang berasal dari sebuah desa di Padang, memiliki cita-cita yang tinggi, dengan mimpi menjadi seorang teknokrat, ketika tamat SMP. Semua itu gagal total ketika ibunya memiliki impian yang lain terhadap anaknya itu, yaitu memasukkannya ke Pesantren Gontor. Menuruti keinginan ibunya itu, ia pun berangkat ke Gontor dengan kendaraan umum dari Padang. Setiba di Gontor, ia bertemu dengan teman-teman baru yang kelak diperkenalkannya sebagai Sahibul Menara. Cerita di novel ini lebih banyak memperkenalkan suasana pesantren PM, kehidupan santri-santri, disiplin, dan nuansa relijius yang membungkus keseluruhan aktivitas mereka (Alwi, A. M. S., Arsyam, M., Sainuddin, I. H., S, \& Makmur, Z;2020). Kisah cinta yang tidak lebih dari tiga halaman antara Alif Fikri dan Sarah merupakan bumbu penyedap yang efektif melengkapi cita-rasa Negeri 5 Menara sebagai sebuah novel pop.

Perpisahan yang menjadi tren novel-novel autobiografi, seperti perpisahan Lintang dan Ikal dalam Laskar Pelangi, mempertegas kekhasan tersebut. Sosok Baso dari Gowa harus pulang 
lebih awal meninggalkan PM karena tidak sanggup membayar SPP. Perpisahan dalam novel autobiografi, sebagaimana dijelaskan di awal sarat mengandung unsur-unsur mendorong atau motivasi, merupakan bagian strategi novelis autobiografi untuk memberi kesan life must go on (Makmur, Z; 2020). Frame ini biasanya menjadi titik-balik kehidupan protagonis. Di titik ini konflik mencapai puncaknya, lalu setelah itu ditata kembali dengan suasana yang baru, walaupun sehalaman pasca-perpisahan itu diberikan kesempatan untuk masa berduka. Novel ini ditutup dengan pertemuan Sohibul Menara di Eropa, tanpa melupakan sahabat mereka yang lain yaitu, Baso.

Dari ringkasan singkat di atas, pengulas menemukan bahwa tujuan novel ini tidak lain memberikan inspirasi kepada pembaca yang segmentasinya adalah pelajar dan mahasiswa. Di usia yang sangat muda Alif Fikri-representasi dari Ahmad Fuadi-sudah memiliki mimpi yang terbilang tinggi, dan mengkonsumsi bacaan yang tidak biasa dibaca oleh seorang anak SMA kebanyakan, seperti Catatan Pinggir Goenawan Moehammad (Makmur, Z., Sainuddin, I. H., S, Arsyam, M., \& HERIANTO, H; 2020). Ini sisi positif yang bisa ditarik seorang remaja visioner ketika membaca novel ini. Namun, pertanyaan yang muncul kemudian apakah seorang remaja visioner selevel Alif Fikri di saat ini akan memilih untuk membaca novel Negeri 5 Menara. Pengulas lagi-lagi sungkan menjawabnya.

Kehadiran teks/sastra di tangan kita tidak hadir dalam keadaan netral. Heideger mengajarkan Jacques Derrida bahwa teks sebaiknya dimurnikan dahulu dari kepentingan pengarang dengan melakukan pencoretan kemungkinan-kemungkinan Kehadiran. Kehadiran yang dimaksud di sini adalah kemunculan pengarang dalam teks sehingga interpretasi berujung pada kegagalan (Makmur, Z; 2020). Makna menjadi bulat dan utuh sehingga pemlesetan dan proyek ambivalensi dalam imajinasi menghasilkan kenihilan. Seperti yang diungkap Fayyadl bahwa teks tanpa ambivalensi seperti seorang pecinta yang tak memiliki hasrat. Jika ingin menemukan instabilitas ini maka sebagaimana kata Heideger di atas, pengarang, dan situs merupakan Kehadiran yang mesti dicoret karena nilai dibangun dari kedua entitas ini. Setelah pencoretan ini, ambivalensi barulah akan muncul, lalu ditemukan jejak yang berada di luar dugaan. 
Namun, selama protagonist merepresentasikan diri pengarang, maka yang terbangun dari teks adalah pemitosan pengarang. Itulah yang dikhawatirkan filosof sebangsa Derrida. Dapat dilihat dari kutipan di awal, seorang tokoh meng-hadir karena dia hidup (born), berfikir (thought), mati (died). Adapun testimoni dan pengakuan diri, menurut Derrida, hanya anekdot atau mitos belaka. Derrida berpendirian bahwa bahasa atau teks tidak akan sanggup mengungkapkan keseluruhan peristiwa. Dalam Autobiografi, pengarang menggambarkan peristiwa hanya berangkat pada subjektivitas dirinya. Ketika Alif Fikri baru saja memasuki lingkungan PM, pembaca dituntun oleh narasi yang berisi penuh dengan ketakjuban, tentang menara, tentang perpustakaan, tentang guidenya yang ramah, atau tentang antusiasme santri bergabung di organisasi. Begitulah cara Ahmad Fuadi menciptakan mitos tentang sekolahnya. Penciptaan frame seperti ini membuat pembaca kehilangan akal dengan meyakini apa yang ada di dalam novel tersebut benar-benar adanya. Hal ini disebabkan sebuah kesadaran bahwa novel ini adalah pengalaman asli si pengarang. Pembaca-pembaca ini, namun, lupa narasi menciptakan kesan.

Narasi membentuk kesan indah terhadap Sarah yang katanya "caantik". Narasi pula yang memberikan kesan kebencian kepada pencuri yang dikroyok oleh santri. Yang perlu diingat hulu dari segala arus narasi ini, tentunya, adalah pengarang. Pengarang mengarahkan pandangan pembaca agar melihat proses keras, dan prestasi protagonis. Tetapi sayangnya, Ahmad Fuadi tidak memperlihatkan banyak kegagalan yang dilaluinya untuk meraih prestasi tersebut. Bukankah kita setuju dengan ungkapan tak ada seekor anak burung yang akan terbang dikepakan sayap pertamanya. Ahmad Fuadi mungkin terlampau terlena membagikan keberhasilannya kepada pembacanya, sehingga lupa memberitahukan tulisan pertamanya yang tidak termuat di Media pondoknya.

\section{Penutup}

Setelah membaca novel ini di tahun 2012, pengulas mengira bahwa alumni-alumni luar negeri sedang berkubu-kubu menciptakan buku yang menceritakan proses hidupnya yang tidak biasa itu, tujuannya untuk menginspirasi pemuda di Indonesia. Apakah klise atau tidak? lagi-lagi pengulas tidak sanggup menjawabnya. Fenomena autobiografi kini mulai menjalar ke dunia kampus. Dari Rektor hingga mahasiswa semester 5, mereka tengah mengalami demam selfie 
lewat teks. Apakah kita sedang mengalami krisis imajinasi, sehingga fiksi sendiri tak mampu lagi membagikan pengalaman melalui image-image yang imajinatif, bukannya peta-peta hidup yang instan. Mungkin sebaiknya kita perlu menarik peta hidup yang kompleks ini ke titik yang lebih esensial dengan belajar dari Chairil Anwar, Nasib adalah kesunyian masing-masing

(dipresentasikan di hadapan komunitas Literasi Enrekang)

\section{Rujukan}

Makmur, Z. (2020, October 17). Film Snowden; antara Paranoia dan Tipuan-Tipuan Klasik Amerika. https://doi.org/10.31219/osf.io/9hgc7

Makmur, Z., \& Sainuddin, I. H., S. (2020, October 10). Karenang di atas Canon (sebuah Apresiasi). https://doi.org/10.31219/osf.io/k6r94

Makmur, Z. (2020, October 13). Paradoks Hubungan antara Manusia, Lingkungan, dan Sains dalam Enam Sekuel Film Final Destination (Sebuah Pendekatan Self-Deconstruction). https://doi.org/10.31219/osf.io/eacgs

Makmur, Z. (2020, September 10). Dekonstruksi puisi "The Divine Comedy" karya Dante Alighieri dalam Novel "Inferno" karya Dan Brown. https://doi.org/10.31219/osf.io/cwypx

HERIANTO, H., Jusmiana, A., Jusmawati, J., \& Makmur, Z. (2020, June 21). Comparing Learning-at-home Activities of Students Living in Cities and Those Living in Villages during the Covid-19 Pandemic. https://doi.org/10.31219/osf.io/m4x9b

Alwi, A. M. S., Arsyam, M., Sainuddin, I. H., S, \& Makmur, Z. (2020, August 18). PELESTARIAN LINGKUNGAN SEBAGAI IMPLEMETASI DAKWAH BI AL-HAL DAN WUJUD KESADARAN MASYARAKAT. https://doi.org/10.31219/osf.io/vf6qm

Makmur, Z. (2020, August 2). Membangun Kesadaran Apokaliptik melalui Sastra di Masa Pandemi. https://doi.org/10.31219/osf.io/utvyk

Makmur, Z., Sainuddin, I. H., S, Arsyam, M., \& HERIANTO, H. (2020, July 4). Paradoxical Relationship between Humans, the Environment, And Science in Final Destination (Movies). https://doi.org/10.31219/osf.io/ukr4q 
Makmur, Z. (2020, October 22). Penjurian Sastra di Masa Kebiasaan Baru. https://doi.org/10.31219/osf.io/5vymt 